\title{
Advances in liquid crystalline nano-carbon materials: prepa- ration of nano-carbon based lyotropic liquid crystal and their fabrication of nano-carbon fibers with liquid crystalline spinning
}

\author{
Yong-Mun Choi, Jin Jung, Jun Yeon Hwang, Seung Min Kim, Hyeonsu Jeong, \\ Bon-Cheol Ku and Munju Goh* \\ Institute of Advanced Composites Materials, Korea Institute of Science and Technology, Wanju 55324, Korea
}

\author{
Article Info \\ Received 15 September 2015 \\ Accepted 5 October 2015 \\ *Corresponding Author \\ E-mail: goh@kist.re.kr \\ Tel: $+82-63-219-8141$

\section{Open Access} \\ DOI: http://dx.doi.org/ \\ 10.5714/CL.2015.16.4.223 \\ This is an Open Access article distributed \\ under the terms of the Creative Commons \\ Attribution Non-Commercial License \\ (http://creativecommons.org/licenses/ \\ by-nc/3.0/) which permits unrestricted \\ non-commercial use, distribution, and \\ reproduction in any medium, provided \\ the original work is properly cited.
}

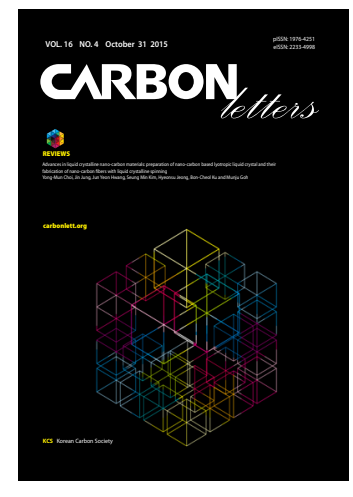

http://carbonlett.org

pISSN: 1976-4251

elSSN: 2233-4998

Copyright $\odot$ Korean Carbon Society

\begin{abstract}
This review presents current progress in the preparation methods of liquid crystalline nanocarbon materials and the liquid crystalline spinning method for producing nano-carbon fibers. In particular, we focus on the fabrication of liquid crystalline carbon nanotubes by spinning from superacids, and the continuous production of macroscopic fiber from liquid crystalline graphene oxide.
\end{abstract}

Key words: liquid crystal, carbon nanotube, graphene oxide, liquid crystalline spinning, nano-carbon fiber

\section{Introduction}

Nano-carbon materials exhibit unique physical and chemical properties which make them attractive starting materials for applications including nanoelectronics, optics $[1,2]$, and the preparation of various carbon composites. However, the physical and chemical properties of nano-carbon materials are extensively influenced by their assembled and dispersed structures. For example, carbon nanotubes (CNTs) are cylindrical onedimensional carbon nanomaterials with a large aspect ratio, while graphene derivatives are two-dimensional carbon materials comprising $s p^{2}$-hybridized carbon atoms arranged on a hexagonal lattice. The distinctive molecular organization of these nanostructures gives them unique physicochemical properties along both the parallel and perpendicular directions of the tube axis and lattice plane, respectively. As a result, CNTs and graphene derivatives exhibit anisotropic properties (e.g., extraordinary tensile strength, and thermal and electrical conductivities), and are expected to be adequate for a variety of applications. Since many of these physicochemical properties are established on a nano-size level, to achieve such innovative properties on a macroscopic scale uniform organizing techniques are required. However, owing to substantial van der Waals attractive interactions, nano-carbon materials tend to form aggregates that prevent uniform alignment of the nanostructures.

Liquid crystalline molecules can show spontaneous orientation, resulting from an excluded volume effect in a domain which has an averaged orientation-direction called "a director". On a macroscopic level, because the director in each liquid crystalline domain is randomly oriented, they assume a multi-domain structure. The multi-domain structure of a liquid crystalline can be easily transformed into a mono-domain structure upon the application of an artificial external force, such as that produced from shearing, or electric or magnetic fields. In addition, the oriented direction of the mono-domains in the liquid crystalline can be reoriented simply by changing the direction of the applied shear force, electric or magnetic field. As a result of these self-assembling abilities and the responsiveness of the orientation direction to external forces, liquid crystallines are used to produce 
macroscopically aligned states in many materials. In particular, $\mathrm{sp}^{2}$-conjugated nanomaterials such as conjugated polymers [3$6]$, porphyrin derivatives $[7,8]$, fullerenes $[9,10]$, and graphenes [11-14], which are difficult to organize and align because of extensive van der Waals interactions, are efficiently organized by using liquid crystalline templates or by embedding liquid crystallinity [15].

In this work, we review the recent advances in the novel preparation of liquid crystalline nano-carbon materials, focusing on CNTs and graphene derivatives, and the liquid crystalline spinning method for producing continuous nano-carbon fibers.

\section{Carbon Nanotubes}

\subsection{Liquid crystalline carbon nanotubes}

CNTs are quite complex systems. From a theoretical point of view, CNTs are thought to be models of straight, long, rigidrodlike particles. The liquid crystallinity of CNTs has been investigated using the steric theory of rigid-rodlike liquid crystals [16-18] and by analyzing phase diagrams using the simple Flory chimney [19].

The mesogenicity of a rodlike object, which is the ability to form liquid crystalline phases, depends mainly on its straightness and aspect ratio (length/diameter ratio). According to the rigid rod theory, liquid crystallinity begins to appear at a weight fraction of about $3.3 \mathrm{Fd} / \mathrm{L}$, where $\mathrm{F}, \mathrm{d}$, and $\mathrm{L}$ are density, rod diameter, and length of the rod, respectively. The polymer/solvent equilibrium diagram (Fig. 1) illustrates that the liquid crystalline and isotropic phases in equilibrium are divided by the Flory chimney, spreading out over a set range of composition, whose bounds depend on the mesogenicity of the polymer and the strength of the interaction between polymers separated by temperature [20-22]. If the polymers are widely polydispersed, the polymers whose molecular weights are low enough to lower their mesogenicity (i.e., lengths shorter than their persistence length) will diffuse prior to the isotropic phase, which is disor-

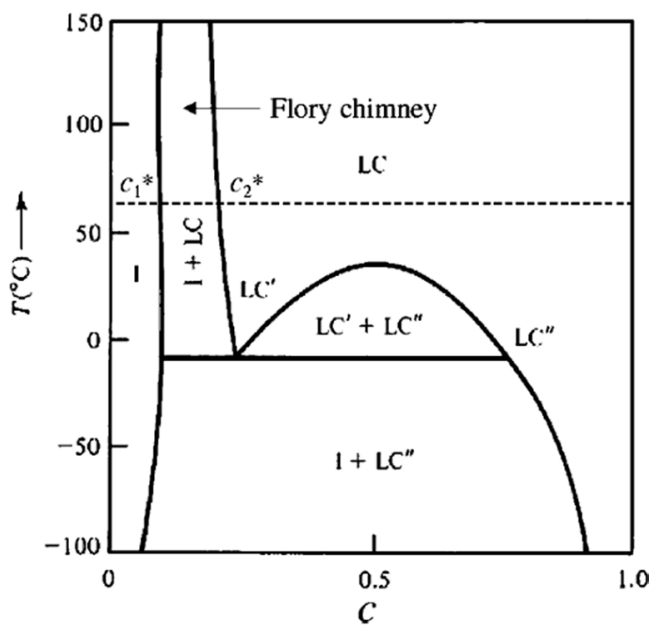

Fig. 1. Phase diagram for a polymer/solvent equilibrium in a lyotropic liquid crystal solution. LC: liquid crystalline. Reprinted from Zhang et al. Nano Lett, 6, 568 (2006), with permission of ACS Publications [19].

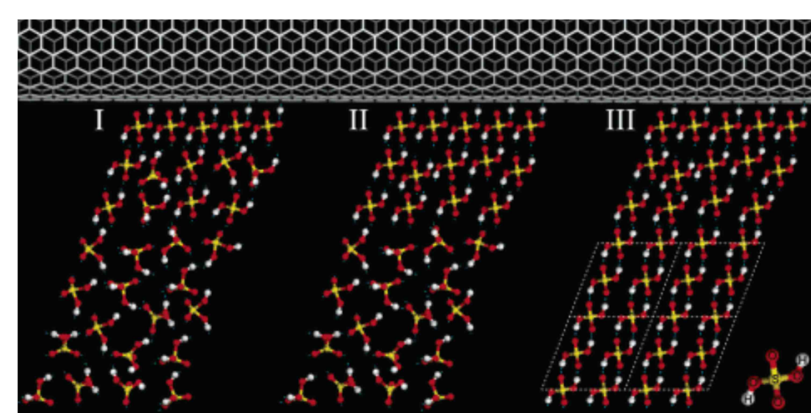

Fig. 2. Schematic illustration of the crystallization of $\mathrm{H}_{2} \mathrm{SO}_{4}$ templated by single-walled carbon nanotube. Reprinted from Zou et al. J Am Chem Soc, 127, 1640 (2005), with permission of ACS Publications [39].

dered. Consequently, a measure of size fractionation will take place between the two phases of the Flory chimney in the polymer/solvent equilibrium diagram. If the phases are physically divided, the liquid crystalline phase can disappear and be refractionated by the further addition of solvent. Then, this process can be repeated sequentially to enhance the mesogenicity of the species forming the liquid crystalline phase. Because CNTs can be exceptionally long, the fractionation of CNTs is possible if their length ranges are within length/diameter ratios greater than 100:1 [23].

Up to now, three methods have been used to prepare liquid crystalline CNTs: acid oxidation [24,25], polymer wrapping [26-29], and superacid protonation [30,31]. Acid oxidation is an efficient method of modifying the CNT surface by introducing functional groups [32-35]. $\mathrm{H}_{2} \mathrm{SO}_{4}$ and $\mathrm{HNO}_{3}$ are commonly used in this method [31,36], and scissions also occur simultaneously in the CNT with this method. As a result, many fractions of CNTs with various sizes can be made. A centrifugation or precipitation process is necessary to classify them by size.

Polymer wrapping is another method used to fabricate liquid crystalline CNTs. The process enables CNTs to be dispersed effectively in solvents without damage because the polymer allows them to disperse as individual units. A number of polymers have been investigated for the polymer wrapping method, such as conjugated polymers [26], amphiphilic block copolymers [27], polyelectrolytes [28], and biopolymers [29]. However, CNTs prepared by this method have inferior properties and limited applications due to intermolecular defects which remain after polymer wrapping.

Another method to improve the dispersion of CNTs and prepare liquid crystalline CNTs is the superacid protonation method reported by Pasquali's group $[31,36]$. With this method, the amount of damage on the surfaces of the CNTs can be greatly reduced, and liquid crystalline CNTs can be made without any additives. Consequently, this method is appropriate for manufacturing CNT fibers, and is considered superior to other methods in that regard. In this method, CNTs are dispersed as individual components in superacids such as $100 \% \mathrm{H}_{2} \mathrm{SO}_{4}$, oleum, methanesulfonic acid (MSA), trifluoromethanesulfonic acid (triflic acid), and chlorosulfonic acid (CSA) [31,36]. Among these, CSA has been considered the most effective superacid because it only dissolves the CNTs [36-38].

In Fig. 2, the single-walled carbon nanotube (SWNT)-templated crystallization of $\mathrm{H}_{2} \mathrm{SO}_{4}$ via the protonation interaction 


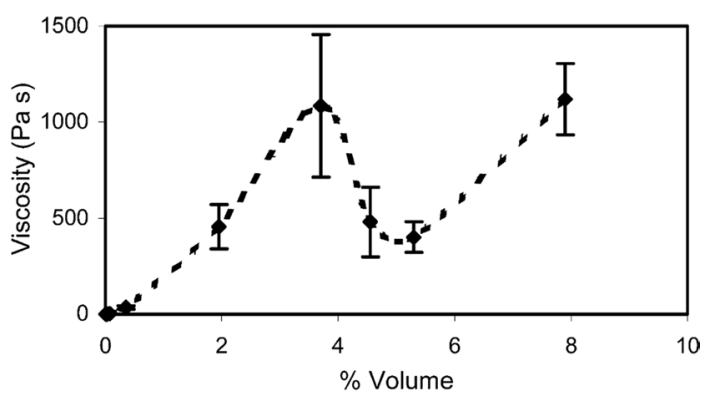

Fig. 3. Viscosity against concentration of a single-walled carbon nanotubes solution in $102 \% \mathrm{H}_{2} \mathrm{SO}_{4}$ at a shear rate of $0.1 \mathrm{~s}^{-1}$. Reprinted from Davis et al. Macromolecules, 37, 154 (2004), with permission of ACS Publications [30].

is illustrated schematically [39]. As shown in this illustration, the crystallization of $\mathrm{H}_{2} \mathrm{SO}_{4}$ by templated SWNT can be accomplished with three steps. (1) Two or three layers of the structured superacid are wrapped around the SWNT to produce positional and orientational order. In this step, the inside layers become most ordered, and the outside layers can interact with the inside layers via hydrogen bonding. The outermost layers of the superacid are semi-ordered. (2) Molecular alignments in the semi-ordered layers become ordered by cooling while their positional order remains unchanged. (3) Crystallization of the "semi-ordered superacid" occurs, and the orientation of the resulting crystals is determined by the molecular alignment of the "ordered superacid".

The protonation in the sidewalls of SWNTs reduces wall-to-wall van der Waals interactions and enhances the dispersion [30,37]. The viscosity of the SWNTs solution in $102 \% \mathrm{H}_{2} \mathrm{SO}_{4}$ plotted against concentration is shown in Fig. 3. When the concentration becomes higher, there is a rapid increase in the viscosity of the solution until the concentration reaches a "critical concentration," after which the viscosity decreases drastically. The increase is an expected result because viscosity tends to rise in an isotropic solution as the concentration becomes higher. From the critical concentration, a nematic phase starts to form and the viscosity begins to drop, exhibiting the low-viscosity behavior of nematic liquid crystals. Such behavior is particularly useful since it allows preparation of a solution containing relatively high proportions of composites, and is suitable for applications.

Crystallinity is another key parameter to study in liquid crystalline CNTs prepared by the superacid method $[38,40]$. Fig. 4 shows the Raman spectra of SWNTs, and the $I_{\mathrm{D}} / I_{\mathrm{G}}$ ratios of low-defect SWNTs (Fig. 4a and c) and high-defect SWNTs (Fig. 4b) are estimated to be 0.2 and 1.0, respectively. In addition, the low-defect SWNTs spontaneously dissolved in CSA, whereas the high-defect SWNTs slightly exfoliated but did not dissolve. This indicates that the solubility of CNTs in CSA inversely depends on the defect density, because the high-defect CNTs have low crystallinity and cannot protonate enough to dissolve in CSA [38].

\subsection{Liquid crystalline spinning of CNTs}

Individual nano-carbon materials have excellent properties [41-50]. For example, the properties of individual nano-carbon materials are higher than those of commercially available highperformance fibers [51-55]. However, in order to achieve these properties on a macroscopic level, elaborate techniques are needed to integrate the individual nano-carbon materials into a large scale. Liquid crystalline spinning is one of these tech-

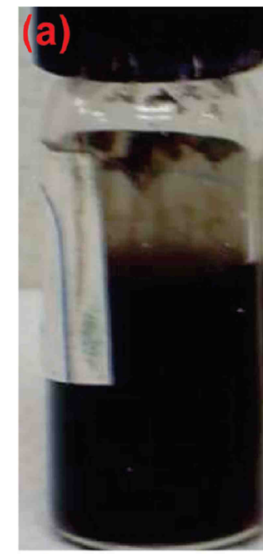

(a)

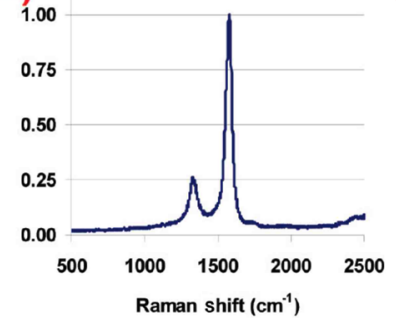

(b)

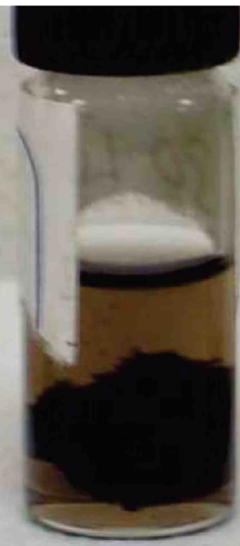

(b)

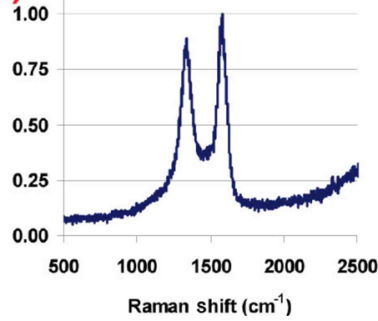

(c)

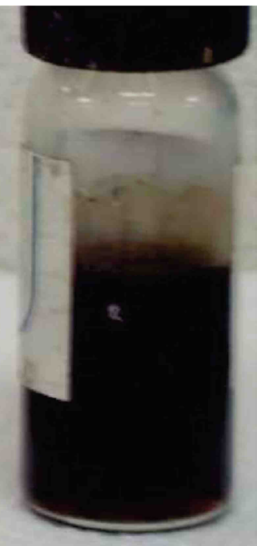

(c)

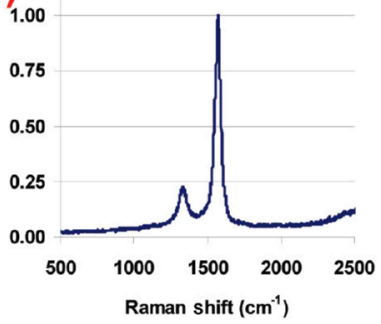

Fig. 4. Image and Raman spectra of single-walled carbon nanotubes (SWNTs) solutions with different defect levels in chlorosulfonic acid. (a) Low-defect SWNTs $(60 \mu \mathrm{m})$, (b) high-defect SWNTs, (c) low defect SWNTs $(100 \mu \mathrm{m})$. Reprinted from Parra-Vasquez et al. ACS Nano, 4, 3969 (2010), with permission of ACS Publications [38]. 

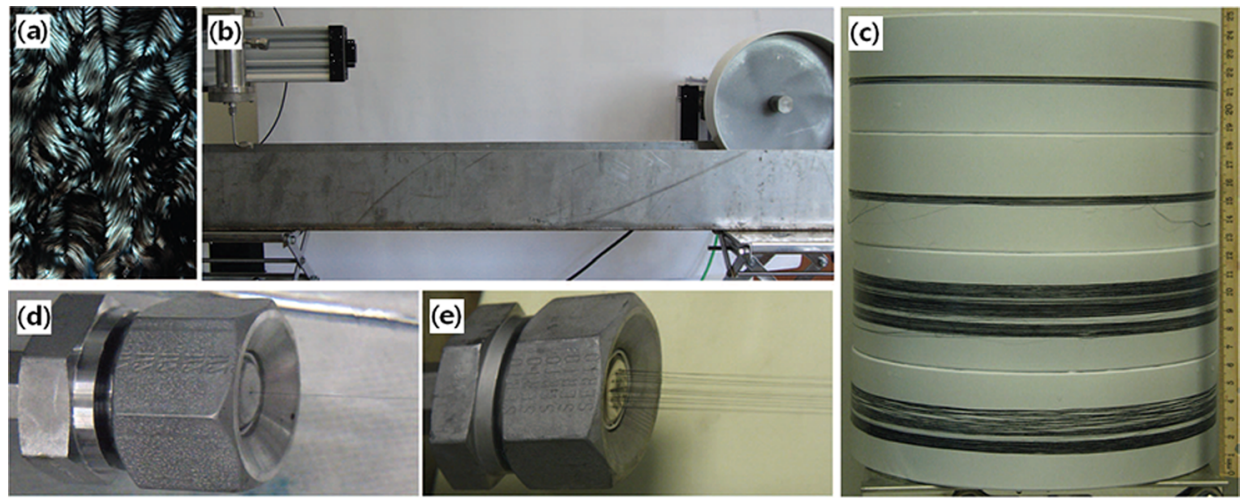

Fig. 5. (a) Image of a birefringent fiber spinning dope (3 wt\% carbon nanotube in chlorosulfonic acid). (b) Set-up for spinning. The fluid is pressed out from the spinning chamber (left) through a spinneret submerged in a coagulation bath; the fiber is continuously collected on the winding drum (right). (c) Winding drums with collected fibers (100 to 500 m on each drum). (d,e) Close-up view of a single- and 19- filament spinning. Reprinted from Behabtu et al. Science, 339, 182 (2013), with permission of American Association for the Advancement of Science [59].

niques, which involves bathing the nano-carbon materials and producing liquid crystallinity through wet spinning. This method has advantages for fabrication of highly-oriented fibers, but it is hard to obtain liquid crystalline phases because the fiber spinning step is quite slow.

The term 'liquid crystalline spinning by superacids' was first used in 2004 when Ericson et al. [56] reported that a CNT fiber had been successfully fabricated by this method. The process began with the dispersion of SWNTs which had been produced by the high-pressure decomposition of $\mathrm{CO}$ (HiPco) $[57,58]$ and purified in $102 \% \mathrm{H}_{2} \mathrm{SO}_{4}\left(2.0 \mathrm{wt} \%\right.$ excess $\left.\mathrm{SO}_{3}\right)$. Well-aligned continuous macroscopic fibers were produced without any surfactant or polymers structure. The $I_{\mathrm{D}} / I_{\mathrm{G}}$ ratios of the fibers was higher than 20.0 and the Young's modulus of the fibers was 120 $\pm 10 \mathrm{GPa}$, which is comparable to that of Kevlar 49 fiber. Behabtu et al. [59] also reported that high-performance multifunctional CNT fiber was prepared in CSA with this method. The CNTs, which had ca. $3.2 \mathrm{~nm}$ of diameter and with ca. $4.3 \mu \mathrm{m}$ of length, were dissolved in CSA at a concentration of 2.0 to $6.0 \mathrm{wt} \%$ and extruded into a coagulant (acetone or $\mathrm{H}_{2} \mathrm{O}$ ) through a spinneret to remove the acid (Fig. 5). The tensile strength and modulus of the fibers were $1.0 \pm 0.2 \mathrm{GPa}$ and $120 \pm 50 \mathrm{GPa}$, respectively.

Optimal morphologies (alignment, packing density, content of impurities, and high-quality molecular constituents) are crucial to the properties of CNT fibers.

The mechanical properties of CNT fibers are considered to depend on the production of long, thin (usually, length $>50 \mu \mathrm{m}$, diameter $<3 \mathrm{~nm}$ ), defect-free, and highly single-walled CNTs.

\section{Graphene Oxide}

\subsection{Liquid crystalline graphene oxide}

Graphene oxide (GO) is defined as the oxidized form of a graphene monolayer platelet [60-67]. The mass production of GO sheet involves the oxidation of graphite to GO and chemical exfoliation [68-70]. After the oxidation, the graphene is exfoliated and functionalized by carboxylic, carbonyl, and hydroxyl groups. These groups create hydrophilicity on the surface of the

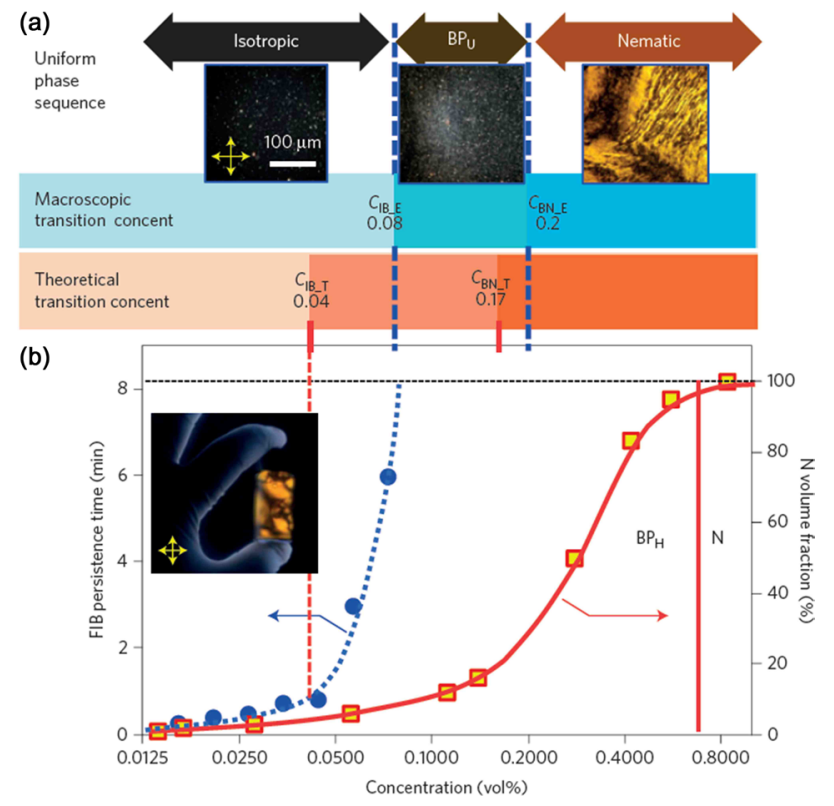

Fig. 6. Theoretical and experimental phase diagram against volume fraction in a graphene oxide suspension. Reprinted from Shen et al. Nat Mater, 13, 394 (2014), with permission of Nature Publishing Group [78].

GO and improve the dispersion and stability of the GO in a polar solvent without any additive [71-73].

The phase transitions of the GO are affected by its aspect ratio (width/thickness ratio). Onsager's excluded volume theory predicts lyotropic phase transitions in suspensions of rod-like or disk-like particles by calculating the total free energy of the system including the excluded volume effect of particles $[16,74]$. Based on a model system of infinitely thin hard platelets $[75,76]$, the critical concentrations of the isotropic-nematic biphasic region were suggested to be

$$
\begin{aligned}
& C_{\mathrm{IB}_{-} \mathrm{T}}=\frac{\pi\left(3.68-2.43 \sigma^{2}\right)\left(1-\sigma^{2}\right)\langle T\rangle}{4\left(1+3 \sigma^{3}\right)\langle D\rangle} \text { and } \\
& C_{\mathrm{BN}_{-} \mathrm{T}}=\frac{\pi\left(3.98+15.82 \sigma^{2}\right)\left(1-\sigma^{2}\right)\langle T\rangle}{4\left(1+3 \sigma^{3}\right)\langle D\rangle} .
\end{aligned}
$$


(a)

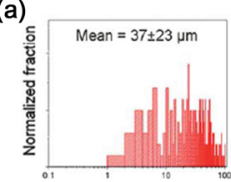

Lateral size ( $(\mu \mathrm{m})$

(b)

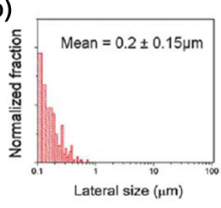

(c)

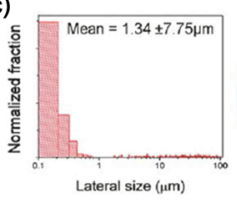

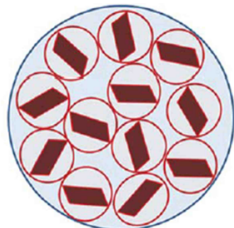
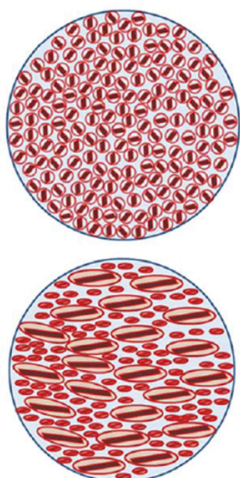
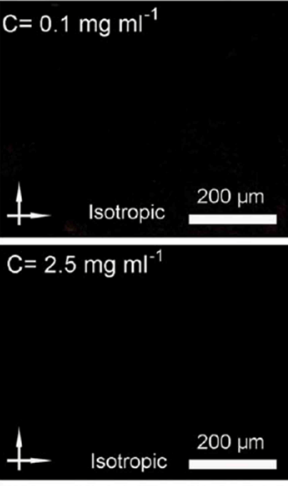

$C=1.3 \mathrm{mg} \mathrm{ml}^{-1}$
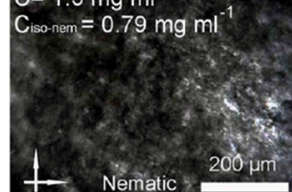

Fig. 7. Introduction of ultra-large graphene oxide (GO) sheets into fully isotropic and non-spinnable GO dispersion. Reprinted from Jalili et al. Mater Horiz, 1, 87 (2014), with permission of Royal Society of Chemistry [81].
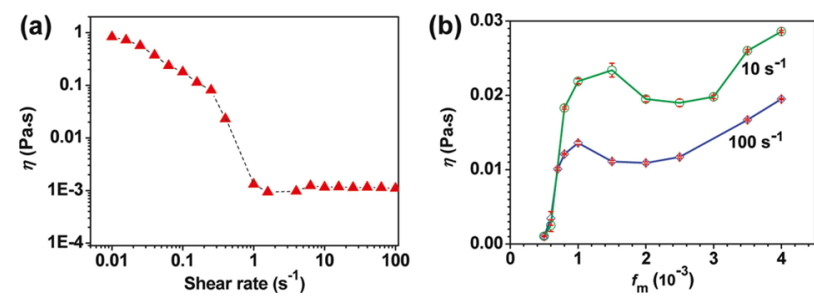

Fig. 8. (a) Shear viscosity against shear rate and (b) shear viscosity against volume fraction. Reprinted from Xu and Gao. ACS Nano, 5, 2908 (2011), with permission of ACS Publications [71].

where $D$ and $\sigma$ denote the diameter of the GO and its normalized standard deviation, and $T$ is the thickness, in which the notation of ' $<>$ ' represents the number average function. Based on these equations, the theoretical concentrations of the isotropic-biphase phase transition $\left(\mathrm{C}_{\mathrm{IB}_{-}}\right)$and the biphase-nematic phase transition $\left(\mathrm{C}_{\mathrm{BN}} \mathrm{T}\right)$ were determined. Actually, the isotropic-nematic phase transition of GO suspensions was observed in the concentration range of 0.3 to $5 \mathrm{mg} / \mathrm{mL}(0.03$ to $0.5 \mathrm{wt} \%)[19,20,77,78]$, which is similar in magnitude to the simulated range in the polydisperse system of infinite platelets (Fig. 6).

Recently, a novel process to prepare ultra-large sized GO was developed using pre-exfoliation of graphite flakes $[79,80]$. The high aspect ratio $(>30,000)$ of the GO suspensions led to phase transitions even at a $\mathrm{GO}$ concentration as low as $\approx 1.0 \mathrm{mg} / \mathrm{mL}$ $(0.1 \mathrm{wt} \%)$. In addition, liquid crystallinity was induced in isotropic (lower than the critical concentration) small-sheet GO dispersions by introducing a small amount of ultra-large GO sheets into it (Fig. 7) [81].

The rheological properties of liquid crystalline GO suspension are similar to those of liquid crystalline CNT suspension $[71,77,82]$. In Fig. 8, the rheological behavior of GO dispersed in DI-water is shown. The viscosity of GO suspension decreases as shear stress increases, and depends on the GO composition and molecular arrangements in the suspension. The viscosity shows non-monotonic behavior as volume fraction $(\varphi)$ increases. At a low volume fraction the GO suspension is in an isotropic phase, and the viscosity increases until the volume fraction reaches the critical point. Then, the viscosity goes down and increases again. The minimum viscosity approximately corresponds to that of a GO suspension where a nematic phase forms entirely.

This liquid crystalline behavior exhibited by a GO suspension agrees well with an optical characterization which measured the liquid crystalline GO suspension by quenching it in liquid $\mathrm{N}_{2}$ and subsequent freeze-drying. Although there is an ordered structure
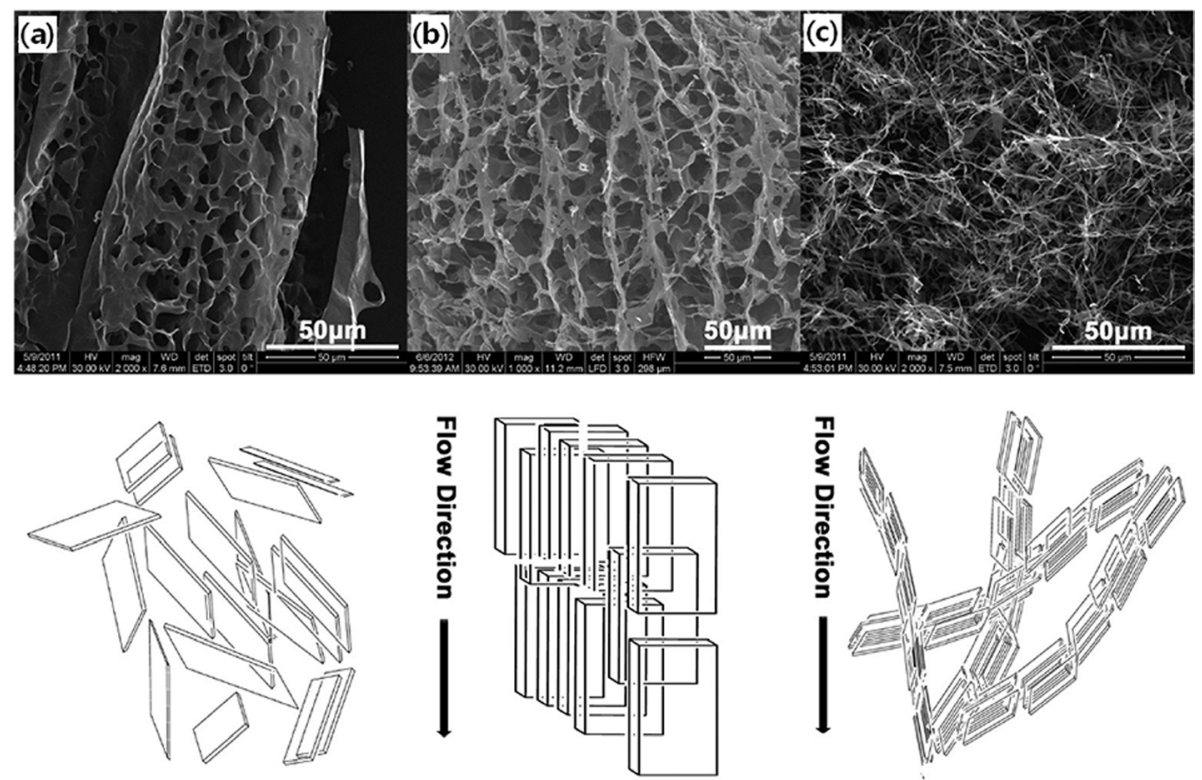

Fig. 9. Scanning electron microscope images of freeze-dried graphene oxide sheets and corresponding diagram of self-assembled structures from a frozen solution of $5 \mathrm{mg} / \mathrm{mL}$ ( $0.5 \mathrm{wt} \%$ ) (a), and a flow induced solution of 5 (b) and $1 \mathrm{mg} / \mathrm{mL}$ (0.1 wt\%) (c). Reprinted from Yang et al. Langmuir, 29 , 8103 (2013), with permission of ACS Publications [77]. 

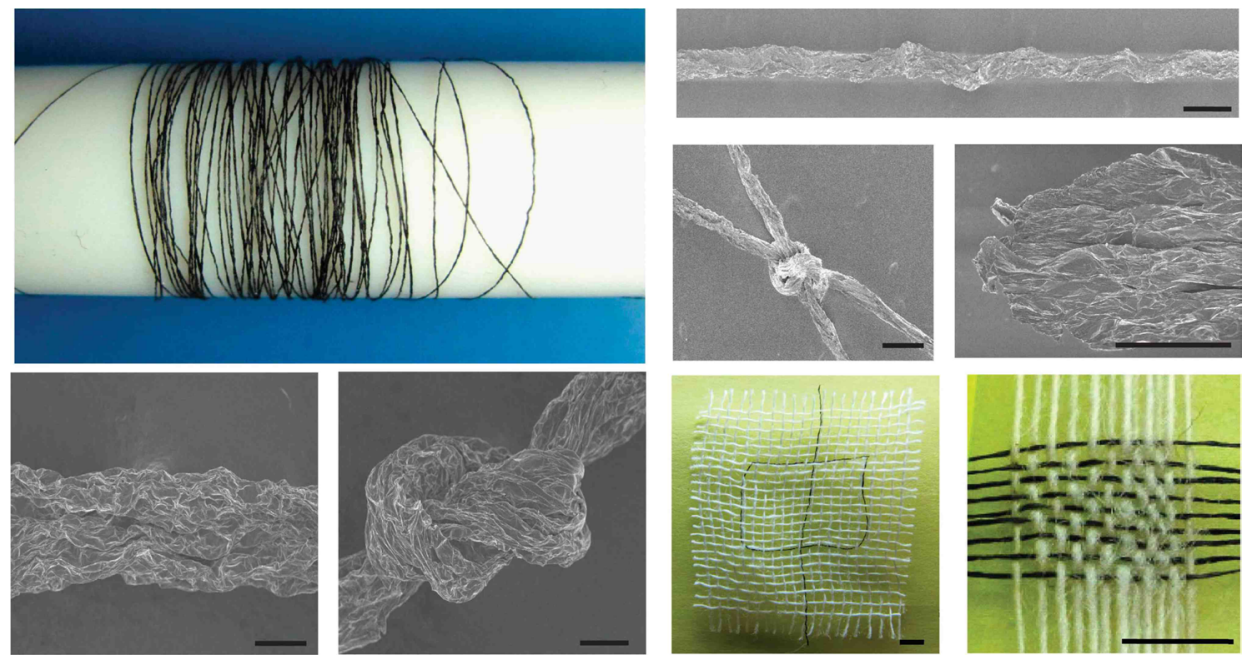

Fig. 10. Macroscopic neat graphene oxide (GO) fibers and chemically reduced GO fibers. Reprinted from Xu and Gao. Nat Commun, 2, 571 (2011), with permission of Nature Publishing Group [83].

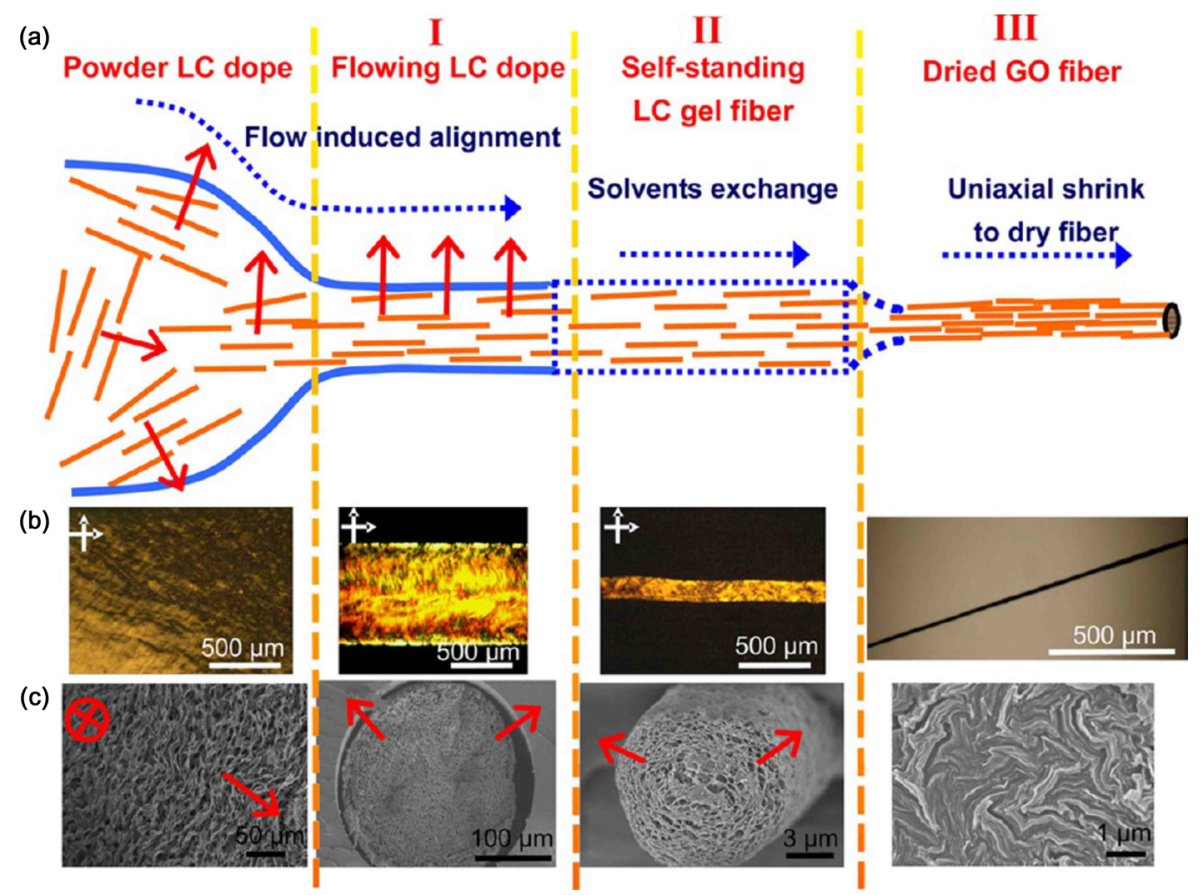

Fig. 11. Illustration of structural evolution (a) and images in the spinning process $(b, c)$. LC: liquid crystalline. Reprinted from Xu and Gao. Acc Chem Res, 47, 1267 (2014), with permission of ACS Publications [91].

and alignment of the GO sheets in the frozen suspension, as shown in Fig. 9a, it reveals that a larger and more aligned structure can be achieved with a flowing suspension, as shown in Fig. $9 \mathrm{~b}$ and c. Interestingly, the planes of the self-assembled layers are parallel to the direction of flow.

\subsection{Liquid crystalline spinning of GO}

In 2011, Xu and Gao [83] reported that macroscopic GO fibers had been prepared by continuous spinning of an aqueous suspension of the liquid crystalline GO (Fig. 10), and the op- tical textures of the liquid crystalline phases of the GO (nematic, lamellar, chiral) and their corresponding structural models were investigated. Furthermore, a lot of methods for fabricating graphene-based composites by liquid crystalline spinning have been reported, including fiber [83-87], aerogel [88], film [89], and network [90] processes.

Generally, 2D colloids are considered to be inadequate for continuous spinning because the interactions between solidlike flakes are weak, and the solubility of colloids is insufficient. However, the alignment of GO sheets by the intrinsic lamellar order of liquid crystalline GO provides strong in- 
teractions between neighboring sheets, which are responsible for their strong mechanical strength [91], and GO sheets with large sizes provide a considerable improvement in mechanical performance (Fig. 11) [84,85]. Control of coagulation baths has been applied as another method to improve the properties of GO fibers [86,87].

\section{Conclusions}

Since the successful fabrication of fullerene in 1996 [44], a number of nano-carbon materials have been produced by different methods, especially during the last decade, including the fabrication of liquid crystalline CNTs by spinning from superacids in 2004 [56] and the continuous production of macroscopic fibers from liquid crystalline GO in 2011 [83]. In addition, various efforts have been made to improve the production processes of nano-carbon fibers and to establish their post-treatment processes. As a result, the high mechanical, electrical, and thermal properties of individual nano-carbon materials have been incorporated into the fibers. Nano-carbon fibers have a good ratio of strength to weight because of their low density. When they are applied to composites, they should have high strength, comparable to those of super-strong fibers or individual nano-carbon materials. Therefore, it is expected that these liquid crystalline spinning methods can be used for the mass production of nanocarbon fibers and the spun fibers can also be used in practical carbon materials.

\section{Acknowledgments}

This work was supported by a grant from the Korea Institute of Science and Technology (KIST) Institutional program (2Z04470). This work was also supported by the Ministry of Trade, Industry and Energy (MOTIE) through the research and development for regional industry (2MR3760).

\section{References}

[1] de Heer WA, Châtelain A, Ugarte D. A carbon nanotube fieldemission electron source. Science, 270, 1179 (1995). http://dx.doi. org/10.1126/science.270.5239.1179.

[2] Baughman RH, Zakhidov AA, de Heer WA. Carbon nanotubes: the route toward applications. Science, 297, 787 (2002). http://dx.doi. org/10.1126/science.1060928.

[3] Akagi K, Piao G, Kaneko S, Sakamaki K, Shirakawa H, Kyotani M. Helical polyacetylene synthesized with a chiral nematic reaction field. Science, 282, 1683 (1998). http://dx.doi.org/10.1126/ science.282.5394.1683.

[4] Goh M, Kyotani M, Akagi K. Highly twisted helical polyacetylene with morphology free from the bundle of fibrils synthesized in chiral nematic liquid crystal reaction field. J Am Chem Soc, 129, 8519 (2007). http://dx.doi.org/10.1021/ja070701x.

[5] Goh M, Matsushita T, Kyotani M, Akagi K. Helical polyacetylenes synthesized in helical sense and pitch controllable chiral nematic liquid crystal with unprecedented temperature dependence. Macromolecules, 40, 4762 (2007). http://dx.doi.org/10.1021/ma0703655.
[6] Goh M, Matsushita S, Akagi K. From helical polyacetylene to helical graphite: synthesis in the chiral nematic liquid crystal field and morphology-retaining carbonization. Chem Soc Rev, 39, 2466 (2010). http://dx.doi.org/10.1039/b907990b.

[7] Zhou X, Kang SW, Kumar S, Li Q. Self-assembly of discotic liquid crystal porphyrin into more controllable ordered nanostructure mediated by fluorophobic effect. Liq Cryst, 36, 269 (2009). http:/ dx.doi.org/10.1080/02678290902846611.

[8] Sakurai T, Tashiro K, Honsho Y, Saeki A, Seki S, Osuka A, Muranaka A, Uchiyama M, Kim J, Ha S, Kato K, Takata M, Aida T. Electron- or hole-transporting nature selected by side-chaindirected $\pi$-stacking geometry: liquid crystalline fused metalloporphyrin dimers. J Am Chem Soc, 133, 6537 (2011). http://dx.doi. org/10.1021/ja201272t.

[9] Sawamura M, Kawai K, Matsuo Y, Kanie K, Kato T, Nakamura E. Stacking of conical molecules with a fullerene apex into polar columns in crystals and liquid crystals. Nature, 419, 702 (2002). http://dx.doi.org/10.1038/nature01110.

[10] Li CZ, Matsuo Y, Nakamura E. Octupole-like supramolecular aggregates of conical iron fullerene complexes into a three-dimensional liquid crystalline lattice. J Am Chem Soc, 132, 15514 (2010). http://dx.doi.org/10.1021/ja1073933.

[11] Herwig P, Kayser CW, Müllen K, Spiess HW. Columnar mesophases of alkylated hexa-peri-hexabenzocoronenes with remarkably large phase widths. Adv Mater, 8, 510 (1996). http://dx.doi. org/10.1002/adma.19960080613.

[12] Schmidt-Mende L, Fechtenkötter A, Müllen K, Moons E, Friend RH, MacKenzie JD. Self-organized discotic liquid crystals for high-efficiency organic photovoltaics. Science, 293, 1119 (2001). http://dx.doi.org/10.1126/science.293.5532.1119.

[13] Geng Y, Fechtenköttera A, Müllen K. Star-like substituted hexaarylbenzenes: synthesis and mesomorphic properties. J Mater Chem, 11, 1634 (2001). http://dx.doi.org/10.1039/b101163o.

[14] Grigoriadis C, Haase N, Butt HJ, Müllen K, Floudas G. Negative thermal expansion in discotic liquid crystals of nanographenes. Adv Mater, 22, 1403 (2010). http://dx.doi.org/10.1002/ adma.200903264.

[15] Yoo HJ, Lee SY, You NH, Lee DS, Yeo H, Choi YM, Goh M, Park J, Akagi K, Cho JW. Dispersion and magnetic field-induced alignment of functionalized carbon nanotubes in liquid crystals. Synth Met, 181，10 (2013). http://dx.doi.org/10.1016/j.synthmet.2013.07.023.

[16] Onsager L. The effect of shape on the interaction of colloidal particles. Ann N Y Acad Sci, 51, 627 (1949). http://dx.doi.org/10.1007/ s002149900018.

[17] Flory PJ. Statistical thermodynamics of semi-flexible chain molecules. Proc Math Phys Sci, 234, 73 (1956). http://dx.doi. org/10.1098/rspa.1956.0015.

[18] Sabba Y, Thomas EL. High-concentration dispersion of single-wall carbon nanotubes. Macromolecules, 37, 4815 (2004). http://dx.doi org $/ 10.1021 / \mathrm{ma} 049706 \mathrm{u}$

[19] Zhang S, Kinloch IA, Windle AH. Mesogenicity drives fractionation in lyotropic aqueous suspensions of multiwall carbon nanotubes. Nano Lett, 6, 568 (2006). http://dx.doi.org/10.1021/ n10521322.

[20] Fraden S, Maret G, Caspar DLD. Angular correlations and the isotropic-nematic phase transition in suspensions of tobacco mosaic virus. Phys Rev E Stat Nonlin Soft Matter Phys, 48, 2816 (1993). http://dx.doi.org/10.1103/PhysRevE.48.2816. 
[21] Miller AF, Donald AM. Surface and interfacial tension of cellulose suspensions. Langmuir, 18, 10155 (2002). http://dx.doi. org/10.1021/la0258300.

[22] Dong XM, Gray DG. Effect of counterions on ordered phase formation in suspensions of charged rodlike cellulose crystallites. Langmuir, 13, 2404 (1997). http://dx.doi.org/10.1021/la960724h.

[23] Hamm M, Elliott JA, Smithson HJ, Windle AH. Multiscale modelling of carbon nanotubes. Mater Res Soc Symp Proc, 788, 623 (2003). http://dx.doi.org/10.1557/proc-788-110.11.

[24] Song W, Kinloch IA, Windle AH. Nematic liquid crystallinity of multiwall carbon nanotubes. Science, 302, 1363 (2003). http:// dx.doi.org/10.1126/science.1089764.

[25] Song W, Windle AH. Isotropic-nematic phase transition of dispersions of multiwall carbon nanotubes. Macromolecules, 38, 6181 (2005). http://dx.doi.org/10.1021/ma047691u.

[26] Dalton AB, Stephan C, Coleman JN, McCarthy B, Ajayan PM, Lefrant S, Bernier P, Blau WJ, Byrne HJ. Selective Interaction of a semiconjugated organic polymer with single-wall nanotubes. J Phys Chem B, 104, 10012 (2000). http://dx.doi.org/10.1021/ jp002857o.

[27] Shvartzman-Cohen R, Levi-Kalisman Y, Nativ-Roth E, Yerushalmi-Rozen R. Generic approach for dispersing single-walled carbon nanotubes: the strength of a weak interaction. Langmuir, 20, 6085 (2004). http://dx.doi.org/10.1021/la049344j.

[28] Sinani VA, Gheith MK, Yaroslavov AA, Rakhnyanskaya AA, Sun K, Mamedov AA, Wicksted JP, Kotov NA. Aqueous dispersions of single-wall and multiwall carbon nanotubes with designed amphiphilic polycations. J Am Chem Soc, 127, 3463 (2005). http:// dx.doi.org/10.1021/ja045670+.

[29] Takahashi T, Tsunoda K, Yajima H, Ishii T. Dispersion and purification of single-wall carbon nanotubes using carboxymethylcellulose. Jpn J Appl Phys, 43, 3636 (2004). http://dx.doi.org/10.1143/ JJAP.43.3636

[30] Davis VA, Ericson LM, Parra-Vasquez ANG, Fan H, Wang Y, Prieto V, Longoria JA, Ramesh S, Saini RK, Kittrell C, Billups WE, Adams WW, Hauge RH, Smalley RE, Pasquali M. Phase behavior and rheology of SWNTs in superacids. Macromolecules, 37, 154 (2004). http://dx.doi.org/10.1021/ma0352328.

[31] Rai PK, Pinnick RA, Parra-Vasquez ANG, Davis VA, Schmidt HK, Hauge RH, Smalley RE, Pasquali M. Isotropic-nematic phase transition of single-walled carbon nanotubes in strong acids. J Am Chem Soc, 128, 591 (2006). http://dx.doi.org/10.1021/ja055847f.

[32] Liu J, Rinzler AG, Dai H, Hafner JH, Bradley RK, Boul PJ, Lu A Iverson T, Shelimov K, Huffman CB, Rodriguez-Macias F, Shon YS, Lee TR, Colbert DT, Smalley RE. Fullerene pipes. Science, 280, 1253 (1998). http://dx.doi.org/10.1126/science.280.5367.1253.

[33] Kuznetsova A, Popova I, Yates JT Jr., Bronikowski MJ, Huffman CB, Liu J, Smalley RE, Hwu HH, Chen JG. Oxygen-containing functional groups on single-wall carbon nanotubes: NEXAFS and vibrational spectroscopic studies. J Am Chem Soc, 123, 10699 (2001). http://dx.doi.org/10.1021/ja011021b.

[34] Zhang J, Zou H, Qing Q, Yang Y, Li Q, Liu Z, Guo X, Du Z. Effect of chemical oxidation on the structure of single-walled carbon nanotubes. J Phys Chem B, 107, 3712 (2003). http://dx.doi. org/10.1021/jp027500u.

[35] Li Q, Yan H, Ye Y, Zhang J, Liu Z. Defect location of individual single-walled carbon nanotubes with a thermal oxidation strategy. J Phys Chem B, 106, 11085 (2002). http://dx.doi.org/10.1021/ jp026512c.
[36] Ramesh S, Ericson LM, Davis VA, Saini RK, Kittrell C, Pasquali M, Billups WE, Adams WW, Hauge RH, Smalley RE. Dissolution of pristine single walled carbon nanotubes in superacids by direct protonation. J Phys Chem B, 108, 8794 (2004). http://dx.doi org/10.1021/jp036971t.

[37] Davis VA, Parra-Vasquez ANG, Green MJ, Rai PK, Behabtu N, Prieto V, Booker RD, Schmidt J, Kesselman E, Zhou W, Fan H, Adams WW, Hauge RH, Fischer JE, Cohen Y, Talmon Y, Smalley RE, Pasquali M. True solutions of single-walled carbon nanotubes for assembly into macroscopic materials. Nat Nanotechnol, 4, 830 (2009). http://dx.doi.org/10.1038/nnano.2009.302.

[38] Parra-Vasquez ANG, Behabtu N, Green MJ, Pint CL, Young CC, Schmidt J, Kesselman E, Goyal A, Ajayan PM, Cohen Y, Talmon Y, Hauge RH, Pasquali M. Spontaneous dissolution of ultralong single- and multiwalled carbon nanotubes. ACS Nano, 4, 3969 (2010). http://dx.doi.org/10.1021/nn100864v

[39] Zhou W, Heiney PA, Fan H, Smalley RE, Fischer JE. Single-walled carbon nanotube-templated crystallization of $\mathrm{H}_{2} \mathrm{SO}_{4}$ : direct evidence for protonation. J Am Chem Soc, 127, 1640 (2005). http:// dx.doi.org/10.1021/ja043131z.

[40] Duque JG, Parra-Vasquez ANG, Behabtu N, Green MJ, Higginbotham AL, Price BK, Leonard AD, Schmidt HK, Lounis B, Tour JM, Doorn SK, Cognet L, Pasquali M. Diameter-dependent solubility of single-walled carbon nanotubes. ACS Nano, 4, 3063 (2010) http://dx.doi.org/10.1021/nn100170f.

[41] Krishnan A, Dujardin E, Ebbesen TW, Yianilos PN, Treacy MMJ. Young's modulus of single-walled nanotubes. Phys Rev B Condens Matter Mater Phys, 58, 14013 (1998). http://dx.doi.org/10.1103/ PhysRevB.58.14013.

[42] Walters DA, Ericson LM, Casavant MJ, Liu J, Colbert DT, Smith KA, Smalley RE. Elastic strain of freely suspended single-wall carbon nanotube ropes. Appl Phys Lett, 74, 3803 (1999). http://dx.doi. org $/ 10.1063 / 1.124185$

[43] Yu MF, Files BS, Arepalli S, Ruoff RS. Tensile loading of ropes of single wall carbon nanotubes and their mechanical properties. Phys Rev Lett, 84, 5552 (2000). http://dx.doi.org/10.1103/PhysRevLett.84.5552.

[44] Thess A, Lee R, Nikolaev P, Dai H, Petit P, Robert J, Xu C, Lee YH, Kim SG, Rinzler AG, Colbert DT, Scuseria GE, Tománek D, Fischer JE, Smalley RE. Crystalline ropes of metallic carbon nanotubes. Science, 273, 483 (1996). http://dx.doi.org/10.1126/science.273.5274.483.

[45] Tans SJ, Devoret MH, Dai H, Thess A, Smalley RE, Geerligs LJ, Dekker C. Individual single-wall carbon nanotubes as quantum wires. Nature, 386, 474 (1997). http://dx.doi. org $/ 10.1038 / 386474 \mathrm{a} 0$.

[46] McEuen PL, Fuhrer MS, Park H. Single-walled carbon nanotube electronics. IEEE Trans Nanotechnol, 1, 78 (2002). http://dx.doi org/10.1109/TNANO.2002.1005429.

[47] Hone J, Whitney M, Piskoti C, Zettl A. Thermal conductivity of single-walled carbon nanotubes. Phys Rev B Condens Matter Mater Phys, 59, R2514 (1999). http://dx.doi.org/10.1103/PhysRevB.59.R2514.

[48] Che J, Çagin T, Goddard WA. Thermal conductivity of carbon nanotubes. Nanotechnology, 11, 65 (2000). http://dx.doi. org/10.1088/0957-4484/11/2/305

[49] Rao CNR, Sood AK, Subrahmanyam KS, Govindaral A. Graphene: the new two-dimensional nanomaterial. Angew Chem Int Ed, 48, 7752 (2009). http://dx.doi.org/10.1002/anie.200901678. 
[50] Geim AK, Novoselov KS. The rise of graphene. Nat Mater, 6, 183 (2007). http://dx.doi.org/10.1038/nmat1849.

[51] Yu MF, Lourie O, Dyer MJ, Moloni K, Kelly TF, Ruoff RS. Strength and breaking mechanism of multiwalled carbon nanotubes under tensile load. Science, 287, 637 (2000). http://dx.doi. org/10.1126/science.287.5453.637.

[52] Frank S, Poncharal P, Wang ZL, de Heer WA. Carbon nanotube quantum resistors. Science, 280, 1744 (1998). http://dx.doi. org/10.1126/science.280.5370.1744.

[53] Hone J, Whitney M, Zettl A. Thermal conductivity of singlewalled carbon nanotubes. Synth Met, 103, 2498 (1999). http:// dx.doi.org/10.1016/s0379-6779(98)01070-4.

[54] Berber S, Kwon YK, Tománek D. Unusually high thermal conductivity of carbon nanotubes. Phys Rev Lett, 84, 4613 (2000). http:// dx.doi.org/10.1103/PhysRevLett.84.4613.

[55] Li QW, Li Y, Zhang XF, Chikkannanavar SB, Zhao YH, Dangelewicz AM, Zheng LX, Doorn SK, Jia QX, Peterson DE, Arendt PN, Zhu YT. Structure-dependent electrical properties of carbon nanotube fibers. Adv Mater, 19, 3358 (2007). http://dx.doi.org/10.1002/ adma.200602966.

[56] Ericson LM, Fan H, Peng H, Davis VA, Zhou W, Sulpizio J, Wang Y, Booker R, Vavro J, Guthy C, Parra-Vasquez ANG, Kim MJ, Ramesh S, Saini RK, Kittrell C, Lavin G, Schmidt H, Adams WW, Billups WE, Pasquali M, Hwang WF, Hauge RH, Fischer JE, Smalley RE. Macroscopic, neat, single-walled carbon nanotube fibers. Science, 305, 1447 (2004). http://dx.doi.org/10.1126/science. 1101398

[57] Nikolaev P, Bronikowski MJ, Bradley RK, Rohmund F, Colbert DT, Smith KA, Smalley RE. Gas-phase catalytic growth of singlewalled carbon nanotubes from carbon monoxide. Chem Phys Lett, 313, 91 (1999). http://dx.doi.org/10.1016/S0009-2614(99)010295.

[58] Bronikowski MJ, Willis PA, Colbert DT, Smith KA, Smalley RE. Gas-phase production of carbon single-walled nanotubes from carbon monoxide via the HiPco process: a parametric study. J Vac Sci Technol A, 19, 1800 (2001). http://dx.doi.org/10.1116/1.1380721.

[59] Behabtu N, Young CC, Tsentalovich DE, Kleinerman O, Wang X, Ma AWK, Bengio EA, ter Waarbeek RF, de Jong JJ, Hoogerwerf RE, Fairchild SB, Ferguson JB, Maruyama B, Kono J, Talmon Y, Cohen Y, Otto MJ, Pasquali M. Strong, light, multifunctional fibers of carbon nanotubes with ultrahigh conductivity. Science, 339, 182 (2013). http://dx.doi.org/10.1126/science.1228061.

[60] Dikin DA, Stankovich S, Zimney EJ, Piner RD, Dommett GHB, Evmenenko G, Nguyen ST, Ruoff RS. Preparation and characterization of graphene oxide paper. Nature, 448, 457 (2007). http:// dx.doi.org/10.1038/nature06016.

[61] Geim AK. Graphene: status and prospects. Science, 324, 1530 (2009). http://dx.doi.org/10.1126/science.1158877.

[62] Gómez-Navarro C, Burghard M, Kern K. Elastic properties of chemically derived single graphene sheets. Nano Lett, 8, 2045 (2008). http://dx.doi.org/10.1021/n1801384y.

[63] Li D, Müller MB, Gilje S, Kaner RB, Wallace GG. Processable aqueous dispersions of graphene nanosheets. Nat Nanotechnol, $\mathbf{3}$, 101 (2008). http://dx.doi.org/10.1038/nnano.2007.451.

[64] Dreyer DR, Park S, Bielawski CW, Ruoff RS. The chemistry of graphene oxide. Chem Soc Rev, 39, 228 (2010). http://dx.doi. org/10.1039/b917103g.

[65] Zhu Y, Murali S, Cai W, Li X, Suk JW, Potts JR, Ruoff RS. Graphene and graphene oxide: synthesis, properties, and applica- tions. Adv Mater, 22, 3906 (2010). http://dx.doi.org/10.1002/ adma.201001068

[66] Segal M. Selling graphene by the ton. Nat Nanotechnol, 4, 612 (2009). http://dx.doi.org/10.1038/nnano.2009.279.

[67] Lee SH, Lee DH, Lee WJ, Kim SO. Tailored assembly of carbon nanotubes and graphene. Adv Funct Mater, 21, 1338 (2011). http:// dx.doi.org/10.1002/adfm.201002048

[68] Brodie BC. Sur le poids atomique du graphite. Ann Chim Phys, 59, 466 (1860).

[69] Hummer WS Jr., Offeman RE. Preparation of graphitic oxide. J Am Chem Soc, 80, 1339 (1958). http://dx.doi.org/10.1021/ ja01539a017.

[70] Stankovich S, Dikin DA, Dommett GHB, Kohlhaas KM, Zimney EJ, Stach EA, Piner RD, Nguyen ST, Ruoff RS. Graphenebased composite materials. Nature, 442, 282 (2006). http://dx.doi. org/10.1038/nature04969.

[71] Xu Z, Gao C. Aqueous liquid crystals of graphene oxide. ACS Nano, 5, 2908 (2011). http://dx.doi.org/10.1021/nn200069w.

[72] Kim JE, Han TH, Lee SH, Kim JY, Ahn CW, Yun JM, Kim SO Graphene oxide liquid crystals. Angew Chem Int Ed, 50, 3043 (2011). http://dx.doi.org/10.1002/anie.201004692.

[73] Lei X, Xu Z, Sun H, Wang S, Griesinger C, Peng L, Gao C, Tan $\mathrm{RX}$. Graphene oxide liquid crystals as a versatile and tunable alignment medium for the measurement of residual dipolar couplings in organic solvents. J Am Chem Soc, 136, 11280 (2014). http:// dx.doi.org/10.1021/ja506074a.

[74] de Gennes PG, Prost J. The Physics of Liquid Crystals. 2nd ed., Oxford University Press, New York, NY (1993).

[75] van der Kooij FM, Lekkerkerker HNW. Formation of nematic liquid crystals in suspensions of hard colloidal platelets. J Phys Chem B, 102, 7829 (1998). http://dx.doi.org/10.1021/jp981534d.

[76] Bates MA, Frenkel D. Nematic-isotropic transition in polydisperse systems of infinitely thin hard platelets. J Chem Phys, 110, 6553 (1999). http://dx.doi.org/10.1063/1.478558.

[77] Yang X, Guo C, Ji L, Li Y, Tu Y. Liquid crystalline and shear-induced properties of an aqueous solution of graphene oxide sheets Langmuir, 29, 8103 (2013). http://dx.doi.org/10.1021/la401038c.

[78] Shen TZ, Hong SH, Song JK. Electro-optical switching of graphene oxide liquid crystals with an extremely large Kerr coefficient. Nat Mater, 13, 394 (2014). http://dx.doi.org/10.1038/nmat3888.

[79] Dan B, Behabtu N, Martinez A, Evans JS, Kosynkin DV, Tour JM, Pasquali M, Smalyukh II. Liquid crystals of aqueous, giant graphene oxide flakes. Soft Matter, 7, 11154 (2011). http://dx.doi. org/10.1039/c1sm06418e.

[80] Aboutalebi SH, Gudarzi MM, Zheng QB, Kim JK. Spontaneous formation of liquid crystals in ultralarge graphene oxide dispersions. Adv Funct Mater, 21, 2978 (2011). http://dx.doi.org/10.1002/ adfm. 201100448.

[81] Jalili R, Aboutalebi SH, Esrafilzadeh D, Konstantinov K, Razal JM, Moulton SE, Wallace GG. Formation and processability of liquid crystalline dispersions of graphene oxide. Mater Horiz, 1, 87 (2014). http://dx.doi.org/10.1039/c3mh00050h

[82] Kumar P, Maiti UN, Lee KE, Kim SO. Rheological properties of graphene oxide liquid crystal. Carbon, 80, 453 (2014). http:// dx.doi.org/10.1016/j.carbon.2014.08.085.

[83] Xu Z, Gao C. Graphene chiral liquid crystals and macroscopic assembled fibres. Nat Commun, 2, 571 (2011). http://dx.doi. org/10.1038/ncomms 1583 .

[84] Xu Z, Sun H, Zhao X, Gao C. Ultrastrong fibers assembled from 
giant graphene oxide sheets. Adv Mater, 25, 188 (2013). http:// dx.doi.org/10.1002/adma.201203448.

[85] Xiang C, Young CC, Wang X, Yan Z, Hwang CC, Cerioti G, Lin J, Kono J, Pasquali M, Tour JM. Large flake graphene oxide fibers with unconventional 100\% knot efficiency and highly aligned small flake graphene oxide fibers. Adv Mater, 25, 4592 (2013). http://dx.doi.org/10.1002/adma.201301065.

[86] Jalili R, Aboutalebi SH, Esrafilzadeh D, Shepherd RL, Chen J, Aminorroaya-Yamini S, Konstantinov K, Minett AI, Razal JM, Wallace GG. Scalable one-step wet-spinning of graphene fibers and yarns from liquid crystalline dispersions of graphene oxide: towards multifunctional textiles. Adv Funct Mater, 23, 5345 (2013). http://dx.doi.org/10.1002/adfm.201300765.

[87] Kim YS, Kang JH, Kim T, Jung Y, Lee K, Oh JY, Park J, Park CR. Easy preparation of readily self-assembled high-performance graphene oxide fibers. Chem Mater, 26, 5549 (2014). http://dx.doi. org/10.1021/cm502614w.

[88] Xu Z, Zhang Y, Li P, Gao C. Strong, conductive, lightweight, neat graphene aerogel fibers with aligned pores. ACS Nano, 6, 7103 (2012). http://dx.doi.org/10.1021/nn3021772.

[89] Liu Z, Li Z, Xu Z, Xia Z, Hu X, Kou L, Peng L, Wei Y, Gao C. Wetspun continuous graphene films. Chem Mater, 26, 6786 (2014). http://dx.doi.org/10.1021/cm5033089.

[90] Cao J, Zhang Y, Men C, Sun Y, Wang Z, Zhang X, Li Q. Programmable writing of graphene oxide/reduced graphene oxide fibers for sensible networks with in situ welded junctions. ACS Nano, 8 , 4325 (2014). http://dx.doi.org/10.1021/nn4059488.

[91] Xu Z, Gao C. Graphene in Macroscopic Order: Liquid Crystals and Wet-Spun. Acc. Chem. Res., 47, 1267 (2014). http://dx.doi. org/10.1021/ar4002813. 